\title{
Spontaneous trigger words associated with out-of-hospital cardiac arrest: a descriptive pilot study of emergency calls
}

Tamminen J, Lydén E, Kurki J, Huhtala H, Kämäräinen A, Hoppu S Medical School, University of Tampere and Emergency Medical Service, Tampere University Hospital, Finland

\section{Purpose of the study}

According to the International Liaison Committee on Resuscitation (ILCOR), key words used by callers that are associated with cardiac arrest constitute a scientific knowledge gap. ${ }^{1}$ Identifying spontaneous trigger words at the beginning of an emergency call may reduce time to dispatch emergency medical services and to initiate bystander resuscitation.

\section{Materials and methods}

Observational study in a Finnish district covering 510000 inhabitants

- Data included all audio recordings and mission reports of emergency calls of suspected out-of-hospital cardiac arrests or confirmed sudden deaths between January 1 and May 31, 2017

- We excluded cases with unwitnessed cardiac arrest or traumatic death and institutional resuscitation attempts

- Spontaneous trigger words were stratified into true cardiac arrest and non-cardiac arrest groups

- The association between the trigger words and confirmed true cardiac arrests was assessed with a univariate logistic regression model

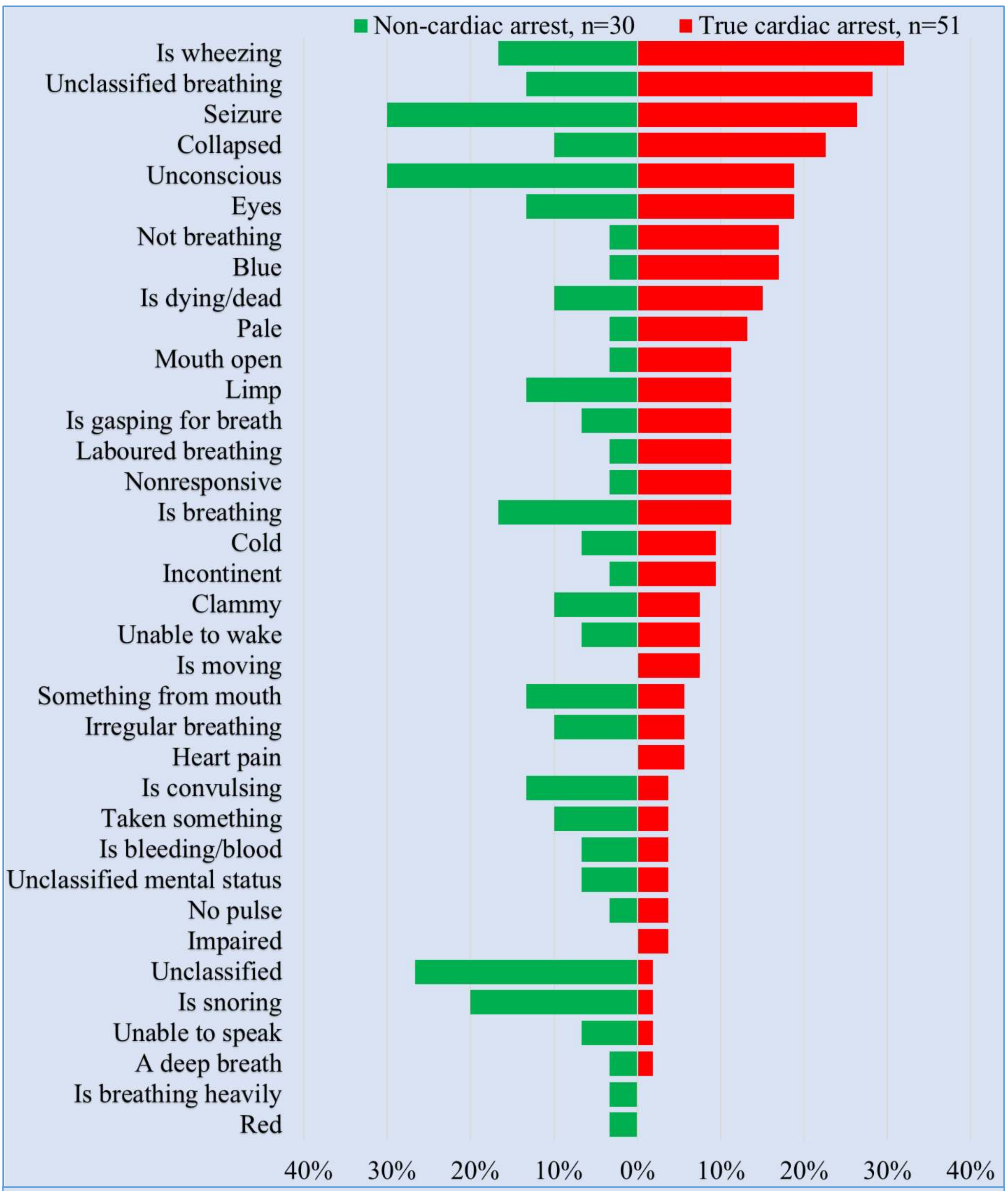

Figure 1. 294 spontaneous trigger words in 81 suspected out-of-hospital cardiac arrests.

\section{Results}

Table 1. Spontaneous trigger words in true cardiac arrest and non-cardiac arrest groups.

\begin{tabular}{|c|c|c|c|c|c|}
\hline \multirow[b]{2}{*}{ Trigger word } & \multicolumn{2}{|c|}{ True } & \multicolumn{2}{|c|}{ False } & \multirow{2}{*}{$\begin{array}{l}\text { Odds ratio with } \\
95 \% \text { confidence } \\
\text { interval }\end{array}$} \\
\hline & $\mathrm{n}$ & $\%$ & $\mathrm{n}$ & $\%$ & \\
\hline Is wheezing & 17 & 33 & 5 & 17 & $2.50(0.81-7.68)$ \\
\hline Collapsed & 12 & 23 & 3 & 10 & $2.77(0.71-10.8)$ \\
\hline Not breathing & 9 & 17 & 1 & 3 & $6.21(0.75-51.7)$ \\
\hline Blue & 9 & 17 & 1 & 3 & $6.21(0.75-51.7)$ \\
\hline Pale & 7 & 14 & 1 & 3 & $4.61(0.54-39.5)$ \\
\hline Is snoring & 1 & 2 & 6 & 21 & $0.08(0.009-0.70)$ \\
\hline
\end{tabular}

\section{Conclusion}

We observed heterogeneous, surprisingly various descriptions of agonal breathing in Finnish language.

\section{References}

1. Olasveengen TM, de Caen AR, Mancini ME, Maconochie IK, Aickin R, Atkins DL, et al.

2017 International Consensus on

Cardiopulmonary Resuscitation and Emergency Cardiovascular Care Science With Treatment

Recommendations Summary. Resuscitation. 2017;121:201-14. 